\title{
Management of familial benign chronic pemphigus
}

This article was published in the following Dove Press journal:

Clinical, Cosmetic and Investigational Dermatology

14 September 2016

Number of times this article has been viewed

\section{Harleen Arora \\ Fleta N Bray \\ Jessica Cervantes \\ Leyre A Falto Aizpurua}

Department of Dermatology and Cutaneous Surgery, University of Miami-Miller School of Medicine, Miami, FL, USA
Correspondence: Leyre A Falto Aizpurua Department of Dermatology and Cutaneous Surgery, University of Miami-Miller School of Medicine, 1475 NW 12th Avenue, Suite 2175, Miami, FL 33।36, USA

Tel +17873135148

Email lafalto@gmail.com
Abstract: Benign familial chronic pemphigus or Hailey-Hailey disease is caused by an autosomal dominant mutation in the $A T P 2 C 1$ gene leading to suprabasilar acantholysis. The disease most commonly affects intertriginous areas symmetrically. The chronic nature of the disease and multiple recurrences make the disease bothersome for patients and a treatment challenge for physicians. Treatments include topical and/or systemic agents and surgery including laser. This review summarizes the available treatment options.

Keywords: familial benign chronic pemphigus, corticosteroids, dermabrasion, Hailey-Hailey disease, laser

\section{Introduction}

Benign familial chronic pemphigus, also known as Hailey-Hailey disease (HHD), is a genodermatosis that affects the action of desmosomes between keratinocytes in the epidermis. ${ }^{1,2}$ The autosomal dominant mutation takes place in the $A T P 2 C 1$ gene, which affects the function of calcium-dependent ATPases whose usual function is sequestration of calcium within the Golgi apparatus. ${ }^{2}$ The resulting calcium dysregulation affects epidermal desmosomes and leads to suprabasilar acantholysis (epidermal blistering). Clinically, this results in erosions and vesicles, often coalescing into weeping and crusting plaques. ${ }^{2}$ These lesions are often localized in symmetrical intertriginous areas, such as the axillae, groin, and inframammary folds. Rare variants include HHD distributed in linear or unilateral conformations and/or involving mucosal surfaces or nail plates..$^{1-3}$ The vesicles and plaques are often accompanied by pain and itching, as well as an increased risk of squamous cell carcinoma. ${ }^{2,45}$ Symptoms are exacerbated by factors including sun exposure, heat, sweat, and friction. ${ }^{2,6}$ Exacerbations have also been noted with patch testing and herpes simplex virus type 1 , with possible evolution into herpetic eczema. ${ }^{5,7,8}$

On histology, suprabasilar acantholysis is often described as "a row of tombstones" or a "dilapidated brick wall" - the "tombstones" or "bricks" referring to the basilar keratinocytes. ${ }^{2}$ Dyskeratosis may be present, and the dermis is rarely affected, though lymphocytic infiltrate may be found surrounding the vascular structures. ${ }^{9}$ Furthermore, unlike in bullous diseases such as pemphigus vulgaris, antidesmosomal autoantibodies might not be detected. ${ }^{2}$

HHD tends to be chronic and recalcitrant to treatment. Therefore, many modalities of treatment have been studied. Possible treatments include topical and oral therapy, 
light and laser therapy, and surgery with skin grafting. This review covers topical, systemic, laser, and surgical treatments for benign familial chronic pemphigus, with updates based on recent literature and case reports.

\section{Nonpharmacological treatment}

In addition to medical intervention, certain lifestyle modifications can improve outcomes in HHD. Sweating, heat, and friction may aggravate the lesions; hence, steps should be taken to limit such exposures. For instance, patients may avoid heat and sweating as much as possible (staying indoors, using fans/ air conditioning, etc). Additionally, personal hygiene and frequent cleaning and drying of the skin are important to prevent flaring of lesions. To avoid friction, patients might wear soft and loose clothing and underwear, and soft padding might be worn under tight clothing. In addition, weight management is advised in order to decrease excess body fat, which may lead to friction. Physical activity that involves friction against the surface of the skin should be limited as well. ${ }^{10}$

\section{Topical treatments}

Evidence for topical treatments of familial benign chronic pemphigus is limited to case reports, case series, and expert opinion. The aim of the therapy is to control exacerbating factors and to limit microbial colonization and inflammation (Table 1).

\section{Antimicrobials}

Microbial colonization and infection are important diseasemodifying factors, and as such, topical antibiotics and antiseptics are a mainstay of treatment. ${ }^{11,12}$ Patients should wear lightweight clothing to reduce sweating and friction ${ }^{6}$ and should wash with antimicrobial cleansers to prevent microbial colonization. ${ }^{11}$ Malodorous or vegetating lesions suggest microbial colonization with either bacteria or fungi. ${ }^{11}$ Staphylococcus, Streptococcus, dermatophytes, and Candida species are common colonizers that may exacerbate lesions or preclude healing. ${ }^{9}$ Staphylococcal infection in particular worsens acantholysis and may lead to severe and extended blistering. ${ }^{11,13}$ When infection is suspected, bacterial and fungal cultures should guide treatment. ${ }^{9}$ For mild disease, experts suggest treatment with topical clindamycin $1 \%$ lotion or cream, gentamicin $0.1 \%$ cream, or mupirocin $2 \%$ cream two to four times per day for periods of 2-4 weeks with chlorhexidine gluconate $4 \%$ wash as an adjunct. ${ }^{9}$ Bleach baths (half a cup of bleach in a

Table I Topical agents used to treat HHD

\begin{tabular}{|c|c|c|}
\hline References & Agents & Notes \\
\hline \multicolumn{3}{|c|}{ Topical steroids: used for acute exacerbations } \\
\hline $6,9,11,14$ & $\begin{array}{l}\text { Moderate- to high-intensity steroids; creams or } \\
\text { ointments depending on severity of flare }\end{array}$ & $\begin{array}{l}\text { Twice a day, up to } 2-16 \text { weeks. May use alternating intervals until remission. } \\
\text { Caution with skin atrophy and contact dermatitis }\end{array}$ \\
\hline \multicolumn{3}{|c|}{ Topical steroid sparing agents: typically used for maintenance } \\
\hline $15-18$ & $\begin{array}{l}\text { Tacrolimus } 0.1 \% \text { ointment } \\
\text { Pimecrolimus (cream) }\end{array}$ & $\begin{array}{l}\text { Twice a day, up to } 2 \text { weeks. May alternate with topical steroids for better } \\
\text { outcomes }\end{array}$ \\
\hline \multicolumn{3}{|c|}{ Topical antimicrobials: used for mild superficial infections } \\
\hline $11-13$ & $\begin{array}{l}\text { Clindamycin I\% lotion or cream } \\
\text { Gentamicin } 0.1 \% \text { cream } \\
\text { Mupirocin } 2 \% \text { cream } \\
\text { Adjunct of chlorhexidine gluconate } 4 \% \text { wash } \\
\text { Bleach baths ( } 1 / 2 \text { cup bleach in } 40 \text { gal bath tub) } \\
5 \text {-minute to } 10 \text {-minute application of topical } \\
\text { compresses with I:40 diluted aluminum acetate } \\
\text { Ketoconazole } 2 \% \text { cream (or other azole creams) }\end{array}$ & Two to four times a day for $2-4$ weeks \\
\hline \multicolumn{3}{|c|}{ Other topical options: refractory to topical treatments listed earlier } \\
\hline 28,29 & Calcitriol topical & Twice a day, up to 4 weeks. A 3-month remission reported \\
\hline 30 & Tacalcitol & Twice a day for 3 months. Better results compared to topical steroids \\
\hline 31 & Topical 5-FU & $\begin{array}{l}\text { Three times a week for } 3 \text { months, then once a week for } 3 \text { months. Remission } \\
\text { documented at 9-month follow-up }\end{array}$ \\
\hline 32 & Topical cadexomer & $\begin{array}{l}\text { May see response within I month of treatment and near-complete resolution } \\
\text { near } 10 \text { months }\end{array}$ \\
\hline \multicolumn{3}{|c|}{ Other local options: typically used when topical treatments have failed } \\
\hline II & Intralesional steroids & Can be considered if topical steroids fail \\
\hline 23,25-27 & BTA & $\begin{array}{l}\text { As needed, one case reported } 50 \text { units per axilla. Needs reinjections for } \\
\text { maintenance. Concern for development of neutralizing antibodies }\end{array}$ \\
\hline
\end{tabular}

Abbreviations: HHD, Hailey-Hailey disease; 5-FU, 5-fluorouracil; BTA, botulinum toxin type A; gal, gallon. 
full 40 gal bath tub) or 5-minute to 10-minute applications of topical compresses with 1:40 diluted aluminum acetate may be used as alternatives to chlorhexidine wash. ${ }^{9}$ For mild disease with fungal colonization, experts suggest twicedaily application of ketoconazole $2 \%$ cream or other azole cream for 2-4 weeks. ${ }^{9}$ If lesions persist despite antibiotic and/or antifungal therapy, viral culture or polymerase chain reaction-based testing for herpes simplex virus infection may be considered. In a 1992 review by Burge, ${ }^{6}$ five (9\%) of 58 patients with biopsy-proven disease required antiviral therapy for herpes simplex virus infection at some time during their disease course. Occasionally, skin biopsy may be required for persistent lesions.

\section{Corticosteroids}

Topical corticosteroids are used to modulate inflammation and are often used in combination with topical antimicrobial agents. ${ }^{6,12}$ Their application should generally be limited in duration to treatment of acute exacerbations, though small case series have examined prolonged treatment with topical steroids. In a 1993 case series by Ikeda et al, ${ }^{14}$ strong steroid ointments were applied continuously to achieve lesion remission and to prevent relapse in seven patients. All seven patients achieved remission within 2-16 weeks, and four patients maintained remission from 1.5 to 4 years with continuous application of topical steroids. These patients developed skin atrophy and contact dermatitis without further adverse effects. ${ }^{14}$ Nevertheless, evidence for prolonged treatment courses of potent topical steroids is limited due to their side effects, most commonly skin atrophy. As a general rule, they should be used in short courses at the lowest effective potency to treat acute exacerbations. ${ }^{11}$ Typically, this will require $\sim 1$ week of twice-daily application of a moderate-to-high potency steroid. ${ }^{9}$ Early treatment of relapses may lead to greater therapeutic benefit. In Burge ${ }^{6} 1992$ review of 58 patients with biopsy-proven disease, 50 patients $(86 \%)$ found that if topical steroids were applied very early in the course of disease relapse when only pruritus was present, the development of lesions could be averted. Lesions refractory to topical corticosteroids may benefit from a trial of intralesional steroids. ${ }^{11}$

\section{Calcineurin inhibitors}

Topical calcineurin inhibitors are a useful nonsteroidal approach for long-term control of inflammation. Unlike corticosteroids, these agents do not block collagen synthesis and do not lead to skin atrophy. They can be applied to sensitive areas including the face, eyelids, neck, and, importantly, skin folds. Tacrolimus is a calcineurin inhibitor that is available as an ointment. It has better penetration than pimecrolimus, which is a calcineurin inhibitor that is available as a cream. Topical application of $0.1 \%$ tacrolimus ointment has been studied in several case reports, with lesion resolution occurring typically after 2 weeks of treatment. ${ }^{15-17}$ Patients may benefit from application of $0.1 \%$ tacrolimus ointment twice daily until lesion resolution. ${ }^{9}$ Umar et al $^{18}$ have also found that twice-daily application of $0.1 \%$ tacrolimus ointment is an excellent method of achieving disease control. In fact, they recommend intermittent therapy with clobetasol $0.05 \%$ foam for breakthrough therapy, alternating tacrolimus with clobetasol foam every 6 weeks.

There are at least two case reports of poor effect with topical tacrolimus treatment. Laffitte and Panizzon ${ }^{19}$ recommended a cautious approach to tacrolimus for they report a case with progressively worsened lesions and had to be discontinued after 12 days. These lesions were Staphylococcus aureus positive and resolved with oral dicloxacillin and topical calcipotriol cream. The authors speculate that while infection may have exacerbated the lesions, topical tacrolimus can worsen irritant contact dermatitis ${ }^{20}$ and in this case may have actually worsened the lesions. Pagliarello et $\mathrm{al}^{21}$ reported a bilateral comparison study where one axilla was treated with $50 \%$ zinc oxide paste only and the other with $0.1 \%$ tacrolimus in addition to zinc oxide twice daily. After 3 months of treatment, the axilla treated with the combination showed less improvement than the axilla treated with zinc oxide paste alone. The authors concluded that zinc oxide paste alone may be a safe and inexpensive treatment.

\section{Botulinum toxin injection}

The protein botulinum toxin type A (BTA) produces chemodenervation by blocking the liberation of acetylcholine from the nerve terminals. In HHD, it can be used as an adjuvant therapy. The suggested mechanism of action involves the role of BTA in blocking the cholinergic stimulus in the postganglionic sympathetic terminal. This results in inhibition of sudoriferic nerves ${ }^{22}$ and reduction of sweat production by the eccrine glands, as well as reduction in saliva and mucus..$^{23,24}$ The reduction in sudoresis, and therefore humidity, provides protection against colonization by microorganisms and subsequent exacerbation of disease..$^{23}$ Bessa et $\mathrm{al}^{23}$ efficaciously treated two sisters with recurrent lesions in the axillae and groin with injections of BTA. In a similar manner, Lapiere et $\mathrm{al}^{25}$ reported the case of a patient who achieved complete remission after applications of 50 units of BTA in each axilla. Lopez-Ferrer and Alomar ${ }^{26}$ described nine cases treated with BTA in the axillary and groin areas with good clinical response with complete remission. 
BTA provides an effective and safe alternative for the treatment of HHD, especially in intertriginous areas. However, BTA requires regular maintenance reinjections. Another main concern is the development of neutralizing antibodies over time, which may diminish the efficacy of BTA. $^{27}$

\section{Alternative agents (calcitriol, 5-fluorouracil, cadexomer iodine)}

It is important to recognize the waxing and waning nature of benign familial chronic pemphigus and to consider whether these lesions entered into remission of their own accord. Nevertheless, calcitriol, 5-fluorouracil (5-FU), and cadexomer iodine are reported as potential therapies.

Calcitriol, otherwise known as 1,25-dihydroxyvitamin D3, is the hormonally active metabolite of vitamin D. Calcitriol can induce differentiation of keratinocytes through its effects on calcium regulation. Bianchi et $\mathrm{al}^{28}$ reported on the efficacy of twice-daily application of topical calcitriol with complete clearing of lesions within 1 month and continued remission on 3-month follow-up. Rajpara and $\mathrm{King}^{29}$ also reported clearance of groin and scrotal lesions with twicedaily application of topical calcitriol, after failure with topical steroids and antibiotics. Aoki et a $\mathrm{l}^{30}$ performed a split-lesion treatment, comparing tacalcitol (an alternative vitamin D3 derivative) to betamethasone dipropionate ointment. One month after proper use of medications, the area treated with tacalcitol showed greater improvement than the steroidtreated area. All lesions were then treated with tacalcitol, resolving after 3 months of therapy. Calcitriol/tacalcitol can be effectively used as treatment in HHD, including insensitive regions such as the groin.

Dammak et $\mathrm{al}^{31}$ reported successful treatment of groin lesions using the topical nucleic acid analog 5-FU. 5-FU at a concentration of 5\% was administered three times per week for 3 months, followed by weekly application for an additional 3 months. The patient experienced near-complete remission within 3 months of treatment and sustained remission over the next 9 months.

Tang and $\operatorname{Tan}^{32}$ used topical cadexomer iodine powder to treat recalcitrant lesions, speculating that its efficacy in treating HHD could be due to its antimicrobial effects and its ability to absorb wound exudate and fluids effectively. Within 1 month of treatment, the patient's lesions were reported to respond and within 10 months the lesions in his groin, neck, and axillae had near-complete resolution. Therefore, both 5-FU and topical cadexomer iodine powder can be safely and effectively used for HHD.

\section{Systemic treatments}

Systemic treatments are often used when lesions are refractory to local topical treatments or when the disease is too diffuse to be treated focally (Table 2).

\section{Oral antimicrobials}

Several studies found oral antibiotics to be helpful. Antibiotics such as erythromycin and penicillin have found to be effective. ${ }^{6,33}$ Success has been reported with oral antibiotics by several case studies, although many have reported combination treatment with other oral or topical medications as helpful. Maintenance with low-dose antibiotics may also be necessary after clearance is achieved. One study observed the treatment of six patients with $100 \mathrm{mg}$ of oral doxycycline per day for at least 3 months. Treatment was effective in five of the patients, although relapse was seen within days to months. One patient exhibited gastrointestinal intolerance, but four of these five patients were retreated with full or half dose, and improvement in relapse was seen. Two of the patients showed complete remission for 5 years. One of the initial six patients had only partial clearance and was not further treated due to antibiotic phobia. ${ }^{34}$ It should be noted that doxycycline has an anti-inflammatory effect in addition to being an antimicrobial. Another reported case was treated successfully with a 2-week treatment of erythromycin combined with topical tacrolimus. ${ }^{16}$

\section{Oral steroids}

The use of oral corticosteroids has been reported during flares or at low doses for maintenance therapy. However, these are not frequently used as patients may use topical steroids avoiding systemic side effects from steroid use and they may flare upon discontinuation. ${ }^{6,35}$

\section{Oral retinoids}

Refractory lesions may be treated with oral retinoids, although their teratogenicity must be taken into account when being prescribed to females of childbearing age. ${ }^{2} \mathrm{~A}$ proposed mechanism of action includes regulation of calcium homeostasis in the skin. ${ }^{36}$ Several cases have shown positive results with retinoids. For instance, a patient with a 20 -year history of generalized HHD possibly triggered by bacterial infection was successfully treated with oral etretinate. ${ }^{37}$ Oral acitretin and low-dose etretinate have also led to improvement in case reports. ${ }^{36}$ In a separate study, disease was controlled with oral prednisone during exacerbations. ${ }^{38}$ However, her therapy was switched to a combination of oral alitretinoin (30 mg per day) and narrowband ultraviolet B light therapy 
Table 2 Systemic agents used in HHD

\begin{tabular}{|c|c|c|}
\hline References & Agents & Notes \\
\hline \multicolumn{3}{|l|}{ Antimicrobials } \\
\hline 6,33 & Erythromycin, penicillins & $\begin{array}{l}\text { May be used in addition to usual treatment options to treat } \\
\text { severe superficial infections or not responsive to topical } \\
\text { treatments }\end{array}$ \\
\hline 34 & Doxycycline 100 mg PO daily, consider low-dose maintenance & $\begin{array}{l}\text { At least } 3 \text { months. Five of six relapse within days to months, } \\
\text { two of six no relapse within } 5 \text { years }\end{array}$ \\
\hline 16 & Erythromycin plus topical tacrolimus & 2 weeks. No recurrence \\
\hline 52 & Oral dapsone & $\begin{array}{l}\text { One of three complete remissions with maintenance after } \\
\text { treatment dose was completed }\end{array}$ \\
\hline \multicolumn{3}{|l|}{ Retinoids } \\
\hline 37 & Etretinate & Successful. Careful with teratogenicity of retinoids \\
\hline 38 & Alitretinoin $30 \mathrm{mg} / \mathrm{d}$ and NB-UVB twice a week & $\begin{array}{l}\text { Clearance in } 6 \text { weeks, alitretinoin was then used as } \\
\text { maintenance }\end{array}$ \\
\hline 36 & Acitretin $25 \mathrm{mg}$ PO daily & 6 months. Significant improvement \\
\hline \multicolumn{3}{|l|}{ DMARDs } \\
\hline 45 & MTX I5 mg per week & 3 months. Clearance for 2 years \\
\hline 46 & MTX maintenance $7.5 \mathrm{mg} \mathrm{IM}$ & Weekly for up to 16 weeks \\
\hline \multirow[t]{2}{*}{43} & Thalidomide $100 \mathrm{mg}$ TID with topical steroids and antimicrobials & Used in conjunctions with topical steroids and antimicrobials. \\
\hline & & Lesions in remission after discontinuation \\
\hline 44,46-49 & Cyclosporine & Risk of flare upon discontinuation \\
\hline \multirow[t]{2}{*}{51} & Glycopyrrolate I mg daily, topical mometasone ointment $0.1 \%$ & Improvement after I month of treatment and remission after \\
\hline & once daily, and oral minocycline $50 \mathrm{mg}$ daily & 6 months, xerostomia as side effect \\
\hline
\end{tabular}

Abbreviations: HHD, Hailey-Hailey disease; PO, per os; NB-UVB, narrowband ultraviolet B; DMARDs, disease-modifying antirheumatic drugs; MTX, methotrexate; IM, intramuscularly; TID, three times a day.

twice weekly. Lesions near-cleared by 6 weeks, after which oral alitretinoin was used alone to maintain the improvement. Successful treatment of HHD has also been achieved with oral alitretinoin alone. ${ }^{39}$

However, several cases have also found retinoids to be ineffective with lesions needing further treatment. ${ }^{35,40-44}$

\section{Other immunosuppressants}

Several immunosuppressants have been used in recalcitrant disease with different success rates.

Methotrexate was successfully used at a dose of $15 \mathrm{mg} / \mathrm{wk}$ with lesions improving after a month. ${ }^{45}$ Treatment was administered for a total of 3 months with clearance of lesions. These remained clear 2 years after discontinuation of the drug. Another case reported the use of maintenance dose at $7.5 \mathrm{mg}$ intramuscularly weekly for 16 weeks. $^{46}$

Thalidomide has been reported to be used in severe disease that failed to respond to dapsone and intravenous steroids. ${ }^{43}$ In one study, thalidomide $100 \mathrm{mg}$ three times a day in combination with topical steroids and antimicrobials was used. Eventually, the lesions improved, and the dose was lowered. Lesions remained in remission upon discontinuation, and no side effects were reported.

Cyclosporine is thought to provide relief of HHD through regulation of intracellular calcium levels and through decreasing levels of pro-inflammatory cytokines in keratinocytes. ${ }^{47}$
There are cases that report successful use with continued response and with maintenance doses after improvement is seen. ${ }^{47,48}$ Two other cases of cyclosporine used for HHD also showed success with continued response due to administration of maintenance doses after improvement. Caution should be advised due to the possible development of hypertension and nephrotoxicity. ${ }^{49}$ There is also a risk of relapse upon discontinuation of medication. However, other studies did not find cyclosporine to be effective. ${ }^{44,46}$

Five months of etanercept at $50 \mathrm{mg}$ once weekly did not show improvement in a middle-aged woman with HHD. ${ }^{50}$ Hurd et al report a case of a patient with a 20 -year history of HHD and failed treatment with many topical agents who had partial clearance ( $75 \%$ improvement) with 5 months of alefacept. No adverse affects were noted, and continued treatment and maintenance with topical clobetasol led to clearance. ${ }^{44}$ However, alefacept is no longer manufactured and distributed.

There is a case that reported combination treatment with glycopyrrolate $1 \mathrm{mg}$ daily, topical mometasone ointment $0.1 \%$ once daily, and oral minocycline $50 \mathrm{mg}$ daily. ${ }^{51}$ Moderate improvement was noted after a month of treatment, and only glycopyrrolate was continued. Lesions cleared after a month of therapy, and remission was maintained for 6 months on this treatment. Only noted side effect was mild xerostomia. 
Though dapsone is an antimicrobial, its main affect in treatment of HHD is through immunosuppression. One study reported the improvement of HHD with oral dapsone in three patients. The first patient experienced resolution of pruritus within 2 days and resolution lesions within 2 weeks, without any recurrence at maintenance doses. ${ }^{52}$ The second patient experienced resolution of pruritus and improvement of lesions; however, the medication was discontinued after 3 months due to decrease in hematocrit. The third patient similarly experienced a clearance of pruritus and a significant improvement in lesion severity. ${ }^{52}$ However, several studies have reported that oral antibiotics were ineffective, with the refractory lesions needing further treatment with other methods including BTA or laser/light therapy. ${ }^{25,40,41,53-56}$

\section{Laser treatments}

Due to the recurrent nature of HHD and the paucity of effective treatment options available for the disease, laser and light therapy was explored as a possible treatment. Light and laser therapy for HHD has shown promise in several case reports, although the most documented and most successful laser therapy has been $\mathrm{CO}_{2}$ laser (Table 3).

\section{$\mathrm{CO}_{2}$ laser}

In the $1980 \mathrm{~s}, \mathrm{CO}_{2}$ laser was first explored as a possible treatment for HHD. The theory behind its use included the ablation of epidermis with sparing of a majority of the dermis and adnexal structures in order to induce reepithelialization and lead to the resolution of lesions. ${ }^{57}$ Local anesthesia is generally used, although larger lesions may require general anesthesia.

Several case reports reported the successful treatment of $\mathrm{HHD}$ with $\mathrm{CO}_{2}$ laser without significant recurrence. ${ }^{5-61}$ The use of $\mathrm{CO}_{2}$ laser may also be helpful in the treatment of recalcitrant lesions as reported by Kukova et al. ${ }^{59,60}$

Kartamaa and Reitamo ${ }^{61}$ conducted a study with $\mathrm{CO}_{2}$ laser ablation of several lesions on eight patients and concluded successful treatment. Two of the eight lesions did not resolve and were treated a second time, resulting in clearance. Adverse effects were only observed in one patient in the form of a hypertrophic scar. Postablative histopathology showed an intact epidermis with increased fibrosis in the papillary dermis, although adnexa were preserved. One study showed improvement in all patients except those treated with lower output powers. Adverse effects include postoperative pain, dyspigmentation, erythema, and scarring. However, most patients still rated their treatment as satisfactory. ${ }^{62}$

\section{Alexandrite laser and diode laser}

The use of both the alexandrite and the diode laser for HHD is understudied. One case report exists for treatment with alexandrite laser where clearance was achieved, but after 13 treatments and five postclearance maintenance treatments. ${ }^{54}$

Table 3 Laser, light, and surgical therapies

\begin{tabular}{|c|c|c|}
\hline References & Methods & Notes \\
\hline \multicolumn{3}{|c|}{ Laser and light therapies } \\
\hline $1,58,59,61,63$ & $\begin{array}{l}\text { Carbon dioxide laser: settings vary among case reports; } \\
\text { power range: } 5-25 \mathrm{~W} \text {; spot size } 1-9 \mathrm{~mm} \text {; modes: } \\
\text { continuous, defocused, and pulsed; } 1-5 \text { passes }\end{array}$ & $\begin{array}{l}\text { Significant improvement or remission of disease achieved in the majority } \\
\text { of cases. Scarring and hyperpigmentation are side effects }\end{array}$ \\
\hline 54 & $\begin{array}{l}\text { Alexandrite } 12-20 \mathrm{~J} / \mathrm{cm}^{2} \text { and spot size } 10-15 \mathrm{~mm} \text {. Cooling } \\
\text { techniques used }\end{array}$ & $\begin{array}{l}\text { Up to } 13 \text { treatments needed to achieve complete clearance, with five } \\
\text { maintenance treatments at } 3 \text {-month intervals postclearance. Minimal- } \\
\text { to-no recurrence was observed at } 2 \text {-year follow-up. Postinflammatory } \\
\text { hyperpigmentation observed }\end{array}$ \\
\hline 22,64 & Er:YAG & Partial-to-compete remission at follow-up 8-12 months \\
\hline 55,56 & $\begin{array}{l}\text { PDT with topical methyl aminolevulinic acid and red } \\
\text { light. The light } 630 \mathrm{~nm} \text { and } 37 \mathrm{~J} / \mathrm{cm}^{2} \text { for } 7.5 \text { minutes. Only } \\
590-700 \mathrm{~nm} \text { and } 120 \mathrm{~mW} / \mathrm{cm}^{2} \text { for } 30 \text { minutes }\end{array}$ & $\begin{array}{l}\text { Postoperative pruritus and pain. Variable results; no improvement to } \\
\text { clearance }\end{array}$ \\
\hline 65 & $\begin{array}{l}\text { PDL } 7-10 \mathrm{~mm} \text { spot size, } 7-10 \mathrm{~J} / \mathrm{cm}^{2} \text { fluence, } 6-10 \mathrm{~ms} \text { pulse } \\
\text { duration }\end{array}$ & $\begin{array}{l}\text { Five treatments were performed at } 2 \text {-week to } 4 \text {-week intervals. Ineffective } \\
\text { in one to six patients. The others had improvement with different degrees } \\
\text { of relapse }\end{array}$ \\
\hline 63 & I,450 nm diode laser. $6 \mathrm{~mm}$ spot size $14 \mathrm{~J} / \mathrm{cm}^{2}$ & $\begin{array}{l}\text { Not effective after three treatment sessions. Painful. Decrease in sweating } \\
\text { and odor }\end{array}$ \\
\hline \multicolumn{3}{|c|}{ Surgical therapies } \\
\hline $40,66,67$ & Dermabrasion & $\begin{array}{l}\text { Used in refractory disease. Reepithelialization takes } \sim 10 \text { days absence of } \\
\text { relapse for long period of time (up to } 42 \text { months) }\end{array}$ \\
\hline 68-70 & Excision with split-thickness skin grafting & Up to 8 years documented without recurrence of disease \\
\hline
\end{tabular}

Abbreviations: Er:YAG, erbium-doped yttrium aluminum garnet; PDT, photodynamic therapy; PDL, pulsed dye laser. 
A case report by Downs ${ }^{63}$ suggested that $1,450 \mathrm{~nm}$ diode laser is painful and not effective in treating the disease, although a decrease in sweating and odor was an unintended positive effect of treatment.

\section{Er:YAG laser}

Erbium-doped yttrium aluminum garnet (Er:YAG) was theorized to be a better alternative to ablative $\mathrm{CO}_{2}$ therapy due to its wavelength $(2.94 \mu \mathrm{m})$, which could allow for epithelial vaporization without excess thermal damage and scar formation. In one study, two patients were treated for HHD of 3 years in the groin and axillae. ${ }^{64}$ Two pulsed treatments were performed, followed by one treatment in partial overlapping mode. Wound healing took 10-12 days. One patient experienced complete remission, while the other experienced partial remission, with recurrence at the edges of the treated areas. No adverse affects were noted. Another study compared the efficacy of Er:YAG and dermabrasion to BTA in the treatment of HHD. ${ }^{22}$ All three methods led to clearance of lesions with no recurrence on 12-month follow-up. However, treatment with Er:YAG laser showed faster wound healing and was more painless than dermabrasion.

\section{Pulsed dye laser}

In one study, seven female patients with recalcitrant HHD were treated with $595 \mathrm{~nm}$ pulsed dye laser. ${ }^{65}$ Five treatments were performed at 2-week to 4 -week intervals. One patient found the treatment to be ineffective and discontinued treatment. Of the other six, two experienced clearance of lesions without relapse. The other four experienced varying degrees of improvement, with eventual relapse. It is theorized that pulsed dye laser therapy might enhance wound healing through increased collagen and generalized dermal remodeling.

\section{Photodynamic therapy}

Fernández et $\mathrm{a}^{56}$ reported one photodynamic therapy session with topical methyl aminolevulinic acid and red light used to treat three patients with HHD. Only one patient experienced slight improvement, while the others did not achieve any improvement and experienced postoperative discomfort. Another study used photodynamic therapy in two patients with recalcitrant lesions. ${ }^{55}$ Although postoperative pruritus and pain existed temporarily, two treatments led to clearance in both patients.

\section{Surgical treatments}

Surgical options are often considered due to the fact that medical and pharmacological treatments are frequently ineffective and/or only offer temporary suppression (Table 3). The available surgical treatments include excision ( \pm grafting) and dermabrasion. Unfortunately, surgical interventions may lead to significant morbidity.

\section{Dermabrasion}

Dermabrasion is a skin-resurfacing technique that uses a wire brush or burr to remove the upper layers of the skin. Dermabrasion is a treatment option for refractory HHD that is unresponsive to conservative therapy. HHD is characterized by an intrinsic defect of cell adhesions that is limited to the epidermal keratinocytes. However, it seems to spare the adnexal structures, thus allowing for repaid reepithelialization to take place after dermabrasion is performed. ${ }^{66}$

Numerous case reports have shown how dermabrasion treatments have provided superior results over traditional medical management. More specifically, they have shown rapid improvement and prolonged absence of relapse episodes. LeBlanc et $\mathrm{al}^{40}$ treated a patient suffering from a 20-year history of refractory HHD with sandpaper dermabrasion. They reported successful functional and cosmetic results along with no recurrence in selected treated areas, except in the axillae. Similarly, Hamm et $\mathrm{al}^{66}$ treated a total of 46 regions on ten patients with dermabrasion, removing the entire epidermis and revealing excellent results. Most patients had reepithelialization in 7-10 days in the treated areas with excellent long-term results, including an average of 42 months without relapse. Of the 46 sites, four had minor recurrence and another four had major recurrence. Kirtschig et $\mathrm{al}^{67}$ reported two cases with previously poor disease control, who finally achieved longer relapse-free periods once treated with dermabrasion.

\section{Excision}

Surgical excision of lesional skin with subsequent splitthickness skin grafting is occasionally performed, especially for recalcitrant cases that do not respond to conservative dermatologic therapy. The removal of adnexal structures and the decrease in sweating and maceration are attributed to the success of surgical excision as a potential therapy for HHD. Thorne et $\mathrm{al}^{68}$ reported the first case of successful resection of affected areas in the scrotum and perineum in 1968. Since then, several case reports have concluded that although an invasive method, excision offers a more adequate approach from an otherwise disabling disease. Sonck et al ${ }^{69}$ described treatment of a patient resistant to all conservative therapy who underwent surgical excision with split-skin grafts. Throughout an 8-year follow-up, the patient did not present with any signs of 
recurrence and remained completely asymptomatic. It was also noted that the nongrafted areas remained active with disease. Furthermore, Bitar and Giroux ${ }^{70}$ reported a case of long-term refractory disease in a patient who was successfully treated with wide surgical excision and skin grafting and benefited for 4 years without recurrence. Overall, this treatment method provides definite relief and a satisfactory improvement in life style.

\section{Conclusion}

HHD is a chronic disease that is characterized by spontaneous remission and multiple recurrences. Severe disease can significantly limit lifestyle and be very frustrating to patients and physicians. Given the nature of this disease, it is difficult to assess efficacy and comparison of the different treatment options, especially because current evidence is based on case series and case reports. Therefore, treatment should be individualized. If diagnosis is doubtful, lesions should be biopsied to rule out concurrent infection and/or contact dermatitis due to topical treatments. All patients should be counseled on nondrug treatment of disease such as personal hygiene, clothing, and lifestyle modifications. Topical treatments are preferred. Lowest strength topical steroids should be used for flares. Any superficial (super)infection, bacterial or fungal, should be treated with topical or oral antimicrobials depending on severity. Topical nonsteroidal creams could be considered then for maintenance.

If disease is recalcitrant, more invasive options can be used. Although laser treatment options should be further studied, they provide a viable and relatively noninvasive alternative treatment option for recurrent disease. Excision and dermabrasion, although effective, are limited due to higher risks of infections, scarring, or poor healing and should be left for very recalcitrant cases.

Unfortunately, current data are limited to case reports and case series. Future studies should include control groups or split trials, larger sample size, and long follow-up periods to assess efficacy of treatment measure. Likewise, further genomic studies in this era may allow for more precise treatment options and allow catering of drugs to patients based on genetic inter- and intrapersonal variability.

\section{Disclosure}

The authors report no conflicts of interest in this work.

\section{References}

1. Falto-Aizpurua LA, Griffith RD, Yazdani Abyaneh MA, Nouri K. Laser therapy for the treatment of Hailey-Hailey disease: a systematic review with focus on carbon dioxide laser resurfacing. J Eur Acad Dermatol Venereol. 2015;29(6):1045-1052.
2. Chiaravalloti A, Payette M. Hailey-Hailey disease and review of management. J Drugs Dermatol. 2014;13(10):1254-1257.

3. Kumar R, Zawar V. Longitudinal leukonychia in Hailey-Hailey disease: a sign not to be missed. Dermatol Online J. 2008;14(3):17.

4. Holst VA, Fair KP, Wilson BB, Patterson JW. Squamous cell carcinoma arising in Hailey-Hailey disease. $J$ Am Acad Dermatol. 2000;43(2 pt 2):368-371.

5. von Felbert V, Hampl M, Talhari C, Engers R, Megahed M. Squamous cell carcinoma arising from a localized vulval lesion of Hailey-Hailey disease after tacrolimus therapy. Am J Obstet Gynecol. 2010;203(3):e5-e7.

6. Burge SM. Hailey-Hailey disease: the clinical features, response to treatment and prognosis. Br J Dermatol. 1992;126(3):275-282.

7. de Aquino Paulo Filho T, deFreitas YK, da Nobrega MT, et al. HaileyHailey disease associated with herpetic eczema-the value of the Tzanck smear test. Dermatol Pract Concept. 2014;4(4):29-31.

8. Lee GH, Kim YM, Lee SY, et al. A case of eczema herpeticum with Hailey-Hailey disease. Ann Dermatol. 2009;21(3):311-314.

9. Morrell D. Hailey-Hailey Disease (Benign Familial Pemphigus). Secondary Hailey-Hailey Disease (Benign Familial Pemphigus). Waltham, MA: UpToDate; 2015.

10. Helm T. Familial Benign Pemphigus (Hailey-Hailey Disease) Treatment \& Management. Secondary Familial Benign Pemphigus (Hailey-Hailey Disease) Treatment \& Management [updated April 9, 2015]. Medscape. Available from: http://emedicine.medscape.com/article/1063224treatment. Accessed October 10, 2015.

11. Hohl D. Darier disease and Hailey-Hailey disease. In: Bolognia J, Jorizzo J, Schaffer J, editors. Dermatology. Philadelphia, PA: Elsevier; 2012:894-896.

12. Galimberti RL, Kowalczuk AM, Bianchi O, Bonino MV, Garcia Garcia A. Chronic benign familial pemphigus. Int J Dermatol. 1988;27(7):495-500.

13. Chave TA, Milligan A. Acute generalized Hailey-Hailey disease. Clin Exp Dermatol. 2002;27(4):290-292.

14. Ikeda S, Suga Y, Ogawa H. Successful management of HaileyHailey disease with potent topical steroid ointment. J Dermatol Sci. 1993;5(3):205-211.

15. Rocha Paris F, Fidalgo A, Baptista J, Caldas LL, Ferreira A. Topical tacrolimus in Hailey-Hailey disease. Int J Tissue React. 2005;27(4): 151-154.

16. Persić-Vojinović S, Milavec-Puretić V, Dobrić I, Rados J, Spoljar S. Disseminated Hailey-Hailey disease treated with topical tacrolimus and oral erythromycin: case report and review of the literature. Acta Dermatovenerol Croat. 2006;14(4):253-257.

17. Sand C, Thomsen HK. Topical tacrolimus ointment is an effective therapy for Hailey-Hailey disease. Arch Dermatol. 2003;139(11):1401-1402.

18. Umar SA, Bhattacharjee P, Brodell RT. Treatment of Hailey-Hailey disease with tacrolimus ointment and clobetasol propionate foam. J Drugs Dermatol. 2004;3(2):200-203.

19. Laffitte E, Panizzon RG. Is topical tacrolimus really an effective therapy for Hailey-Hailey disease? Arch Dermatol. 2004;140(10):1282.

20. Fuchs M, Schliemann-Willers S, Heinemann C, Elsner P. Tacrolimus enhances irritation in a 5-day human irritancy in vivo model. Contact Dermatitis. 2002;46(5):290-294.

21. Pagliarello C, Paradisi A, Dianzani C, et al. Topical tacrolimus and $50 \%$ zinc oxide paste for Hailey-Hailey disease: less is more. Acta Derm Venereol. 2012;92(4):437-438.

22. Konrad H, Karamfilov T, Wollina U. Intracutaneous botulinum toxin A versus ablative therapy of Hailey-Hailey disease - a case report. J Cosmet Laser Ther. 2001;3(4):181-184.

23. Bessa GR, Grazziotin TC, Manzoni AP, Weber MB, Bonamigo RR. Hailey-Hailey disease treatment with Botulinum toxin type A. An Bras Dermatol. 2010;85(5):717-722.

24. Wollina U, Konrad H, Petersen S. Botulinum toxin in dermatology beyond wrinkles and sweat. J Cosmet Dermatol. 2005;4(4):223-227.

25. Lapiere JC, Hirsh A, Gordon KB, Cook B, Montalvo A. Botulinum toxin type A for the treatment of axillary Hailey-Hailey disease. Dermatol Surg. 2000;26(4):371-374. 
26. Lopez-Ferrer A, Alomar A. Toxina botulínica A en el tratamiento de pénfigo benigno familiar [Botulinum toxin A for the treatment of familial benign pemphigus]. Actas Dermosifiliogr. 2012;103(6):532-535. Spanish.

27. Ho D, Jagdeo J. Successful botulinum toxin (onabotulinumtoxinA) treatment of Hailey-Hailey disease. J Drugs Dermatol. 2015;14(1): 68-70.

28. Bianchi L, Chimenti MS, Giunta A. Treatment of Hailey-Hailey disease with topical calcitriol. J Am Acad Dermatol. 2004;51(3):475-476.

29. Rajpara SM, King CM. Hailey-Hailey disease responsive to topical calcitriol. Br J Dermatol. 2005;152(4):816-817.

30. Aoki T, Hashimoto H, Koseki S, Hozumi Y, Kondo S. 1alpha,24dihydroxyvitamin D3 (tacalcitol) is effective against Hailey-Hailey disease both in vivo and in vitro. Br J Dermatol. 1998;139(5):897-901.

31. Dammak A, Camus M, Anyfantakis V, et al. Successful treatment of Hailey-Hailey disease with topical 5-fluorouracil. Br J Dermatol. 2009;161(4):967-968.

32. Tang MB, Tan ES. Hailey-Hailey disease: effective treatment with topical cadexomer iodine. J Dermatolog Treat. 2011;22(5):304-305.

33. Carpenter CC. Treatment of familial benign chronic pemphigus; rapid improvement with penicillin therapy. Arch Derm Syphilol. 1948;58(1):80-83.

34. Le Saché-de Peufeilhoux L, Raynaud E, Bouchardeau A, Fraitag S, Bodemer C. Familial benign chronic pemphigus and doxycycline: a review of 6 cases. J Eur Acad Dermatol Venereol. 2014;28(3):370-373.

35. Hunt MJ, Salisbury EL, Painter DM, Lee S. Vesiculobullous HaileyHailey disease: successful treatment with oral retinoids. Australas $J$ Dermatol. 1996;37(4):196-198.

36. Berger EM, Galadari HI, Gottlieb AB. Successful treatment of Hailey-Hailey disease with acitretin. J Drugs Dermatol. 2007;6(7): 734-736.

37. Mashiko M, Akiyama M, Tsuji-Abe Y, Shimizu H. Bacterial infectioninduced generalized Hailey-Hailey disease successfully treated by etretinate. Clin Exp Dermatol. 2006;31(1):57-59.

38. Vanderbeck KA, Giroux L, Murugan NJ, Karbowski LM. Combined therapeutic use of oral alitretinoin and narrowband ultraviolet-B therapy in the treatment of Hailey-Hailey disease. Dermatol Reports. 2014;6(1):5604.

39. Sardy M, Ruzicka T. Successful therapy of refractory HaileyHailey disease with oral alitretinoin. Br J Dermatol. 2014;170(1): 209-211.

40. LeBlanc KG Jr, Wharton JB, Sheehan DJ. Refractory Hailey-Hailey disease successfully treated with sandpaper dermabrasion. Skinmed. 2011;9(4):263-264.

41. Hamada T, Umemura H, Aoyama Y, et al. Successful therapeutic use of targeted narrow-band ultraviolet B therapy for refractory Hailey-Hailey disease. Acta Derm Venereol. 2013;93(1):110-111.

42. Narbutt J, Chrusciel A, Rychter A, Fijuth J, Lesiak A, Sysa-Jedrzejowska A. Persistent improvement of previously recalcitrant HaileyHailey disease with electron beam radiotherapy. Acta Derm Venereol. 2010;90(2):179-182.

43. Nanda A, Khawaja F, Harbi R, et al. Benign familial pemphigus (HaileyHailey disease) responsive to low dose cyclosporine. Indian J Dermatol Venereol Leprol. 2010;76(4):422-424.

44. Hurd DS, Johnston C, Bevins A. A case report of Hailey-Hailey disease treated with alefacept (Amevive). Br J Dermatol. 2008;158(2): 399-401.

45. Vilarinho C, Ventura F, Brito C. Methotrexate for refractory HaileyHailey disease. J Eur Acad Dermatol Venereol. 2010;24(1):106.

46. D'Errico A, Bonciani D, Bonciolini V, et al. Hailey-Hailey disease treated with methotrexate. J Dermatol Case Reports. 2012;6(2): 49-51.

47. Varada S, Ramirez-Fort MK, Argobi Y, Simkin AD. Remission of refractory benign familial chronic pemphigus (Hailey-Hailey disease) with the addition of systemic cyclosporine. J Cutan Med Surg. 2015;19(2):163-166.
48. Berth-Jones J, Smith SG, Graham-Brown RA. Benign familial chronic pemphigus (Hailey-Hailey disease) responds to cyclosporin. Clin Exp Dermatol. 1995;20(1):70-72.

49. Ormerod AD, Duncan J, Stankler L. Benign familial pemphigus responsive to cyclosporin, a possible role for cellular immunity in pathogenesis. Br J Dermatol. 1991;124(3):299-300.

50. Sand FL, Thomsen SF. Off-label use of TNF-alpha inhibitors in a dermatological university department: retrospective evaluation of 118 patients. Dermatol Ther. 2015;28(3):158-165

51. Kaniszewska M, Rovner R, Arshanapalli A, et al. Oral glycopyrrolate for the treatment of Hailey-Hailey disease. JAMA Dermatol. 2015;151(3):328-329.

52. Sire DJ, Johnson BL. Benign familial chronic pemphigus treated with dapsone. Arch Dermatol. 1971;103(3):262-265.

53. Koeyers WJ, Van Der Geer S, Krekels G. Botulinum toxin type A as an adjuvant treatment modality for extensive Hailey-Hailey disease. J Dermatolog Treat. 2008;19(4):251-254.

54. Awadalla F, Rosenbach A. Effective treatment of Hailey-Hailey disease with a long-pulsed ( $5 \mathrm{~ms}$ ) alexandrite laser. J Cosmet Laser Ther. 2011; 13(4):191-192.

55. Ruiz-Rodriguez R, Alvarez JG, Jaén P, Acevedo A, Córdoba S. Photodynamic therapy with 5-aminolevulinic acid for recalcitrant familial benign pemphigus (Hailey-Hailey disease). J Am Acad Dermatol. 2002;47(5):740-742.

56. Fernández Guarino M, Ryan AM, Harto A, Pérez-García B, Arrázola JM, Jaén P. Experience with photodynamic therapy in Hailey-Hailey disease. J Dermatolog Treat. 2008;19(5):288-290.

57. Don PC, Carney PS, Lynch WS, Zaim MT, Hassan MO. Carbon dioxide laser abrasion: a new approach to management of familial benign chronic pemphigus (Hailey-Hailey disease). J Dermatol Surg Oncol. 1987;13(11):1187-1194.

58. Touma DJ, Krauss M, Feingold DS, Kaminer MS. Benign familial pemphigus (Hailey-Hailey disease). Treatment with the pulsed carbon dioxide laser. Dermatol Surg. 1998;24(12):1411-1414.

59. Kukova G, Homey B, Bruch-Gerharz D, et al. [Familial benign chronic pemphigus (Hailey-Hailey disease): successful treatment with carbon dioxide laser]. Hautarzt. 2011;62(4):258-261. German.

60. Christian MM, Moy RL. Treatment of Hailey-Hailey disease (or benign familial pemphigus) using short pulsed and short dwell time carbon dioxide lasers. Dermatol Surg. 1999;25(8):661-663.

61. Kartamaa M, Reitamo S. Familial benign chronic pemphigus (HaileyHailey disease). Treatment with carbon dioxide laser vaporization. Arch Dermatol. 1992;128(5):646-648.

62. Pretel-Irazabal M, Lera-Imbuluzqueta JM, Espana-Alonso A. Carbon dioxide laser treatment in Hailey-Hailey disease: a series of 8 patients. Actas Dermosifiliogr. 2013;104(4):325-333.

63. Downs A. Smoothbeam laser treatment may help improve hidradenitis suppurativa but not Hailey-Hailey disease. J Cosmet Laser Ther. 2004;6(3):163-164.

64. Beier C, Kaufmann R. Efficacy of erbium:YAG laser ablation in Darier disease and Hailey-Hailey disease. Arch Dermatol. 1999;135(4): 423-427.

65. Hunt KM, Jensen JD, Walsh SB, et al. Successful treatment of refractory Hailey-Hailey disease with a 595-nm pulsed dye laser: a series of 7 cases. J Am Acad Dermatol. 2015;72(4):735-737.

66. Hamm H, Metze D, Brocker EB. Hailey-Hailey disease. Eradication by dermabrasion. Arch Dermatol. 1994;130(9):1143-1149.

67. Kirtschig G, Gieler U, Happle R. Treatment of Hailey-Hailey disease by dermabrasion. J Am Acad Dermatol. 1993;28(5 pt 1):784-786

68. Thorne FL, Hall JH, Mladick RA. Surgical treatment of familial chronic pemphigus (Hailey-Hailey disease). Report of a case. Arch Dermatol. 1968;98(5):522-524.

69. Sonck CE, Rintala A. Treatment of familial benign chronic pemphigus by skin grafting. Acta Derm Venereol. 1975;55(5):395-397.

70. Bitar A, Giroux JM. Treatment of benign familial pemphigus (Hailey-Hailey) by skin grafting. Br J Dermatol. 1970;83(3):402-404. 


\section{Publish your work in this journal}

Clinical, Cosmetic and Investigational Dermatology is an international, peer-reviewed, open access, online journal that focuses on the latest clinical and experimental research in all aspects of skin disease and cosmetic interventions. This journal is included on PubMed. The manuscript management system is completely online and includes a very quick and fair peer-review system, which is all easy to use. Visit http://www.dovepress.com/testimonials.php to read real quotes from published authors 